\title{
ANÁLISE GENÉTICA DE GENÓTIPOS DE Bidens pilosa ATRAVÉS DA TÉCNICA RAPD
}

\author{
GENETIC ANALYSIS OF Bidens pilosa THROUGH RAPD TECHNIQUE
}

\author{
Ribas Antonio VIDAL ${ }^{1}$ \\ Anderson Luis NUNES ${ }^{2}$ \\ Luciane Vilela RESENDE ${ }^{3}$ \\ Fabiane Pinto LAMEGO ${ }^{4}$ \\ Paulo Roberto da SILVA 5
}

\begin{abstract}
RESUMO
Em Bidens pilosa, elevada variabilidade genética, causada por significativa taxa de polinização cruzada, conduz à reduzida similaridade genética entre genótipos, favorecendo a seleção natural daqueles resistentes aos herbicidas utilizadas no seu controle. $\mathrm{O}$ objetivo deste trabalho foi determinar a similaridade genética entre biótipos resistentes e suscetíveis aos herbicidas inibidores da ALS. Através da técnica "DNA Polimórfico Amplificado ao Acaso" (RAPD), foi possível avaliar as diferenças genéticas entre biótipos de Bidens pilosa resistentes e suscetíveis aos herbicidas inibidores da enzima ALS. Todos os primers analisados amplificaram e apresentaram boa reprodutibilidade das bandas. O coeficiente médio de similaridade genética foi de $43 \%$. Foi observada reduzida similaridade genética entre os genótipos resistentes e suscetíveis aos herbicidas empregados no seu controle. Sendo uma espécie autógama, com significativa taxa de polinização cruzada (10\%), a variabilidade genética resultante pode explicar os resultados obtidos e a seleção natural de indivíduos resistentes, quando realizado o uso contínuo de herbicidas com o mesmo mecanismo de ação.
\end{abstract}

Palavras-chave: Bidens pilosa; variabilidade genética; RAPD; herbicida; resistência.

\begin{abstract}
Reduced genetic similarity in Bidens pilosa, due to a significant outcross rate favors natural selection of genotypes resistants to herbicides used for control. The objective of present work was to determine the genetic similarity between resistant and susceptible biotypes to herbicides inhibitors of the ALS enzyme. Seeds were collected in Paraná and Rio Grande do Sul States and sowed in the greenhouse at Federal University in Rio Grande do Sul, during 2004. Through the technique of Random Amplified Polymorphic DNA (RAPD), it was possible to evaluate genetic differences among Bidens biotypes. All primers amplified and showed good band reproducibility. The average coefficient of genetic similarity was $43 \%$. The low genetic similarity observed among ALS-resistant and susceptible accesses suggests that the occurrence of resistant genotypes is due to natural selection, acting on a wide spectrum of different genotypes: reduced genetic similarity linked to high genetic variability, caused by significant outcrossing rate.
\end{abstract}

Key-words: Bidens pilosa; genetic variability; RAPD; herbicide; resistance

\footnotetext{
${ }^{1}$ Eng. Agr., Ph.D., Professor Adjunto do Depto de Plantas de Lavoura da Faculdade de Agronomia, UFRGS. E-mail: ribas.vidal@ufrgs.br. 2 Eng. Agr., aluno do Programa de Pós-Graduação em Fitotecnia da UFRGS. E-mail: nunes.ander@gmail.com

${ }^{3}$ Eng ${ }^{\underline{a}}$ Agr ${ }^{\mathrm{a}}$, Dra.., Professora do Depto Agronomia da Universidade Federal Rural de Pernambuco, UFRPE E-mail: lucianevilela@uol.com.br. ${ }^{4}$ Eng ${ }^{\underline{a}}$ Agr ${ }^{a}$, Mestre, aluna do Programa de Pós-Graduação em Fitotecnia da UFRGS. Caixa Postal 15100, CEP 91501-970, Porto Alegre - RS. E-mail: fabilamego@yahoo.com.br.

${ }^{5}$ Biólogo, Mestre, aluno do Programa de Pós-Graduação em Biologia Celular e Molecular, CBIOT, UFRGS E-mail: paulo@cbiot.ufrgs.br.
} 


\section{INTRODUÇÃO}

Bidens pilosa é uma espécie de ciclo anual, herbácea, autógama, com até $10 \%$ de fecundação cruzada que se reproduz por sementes (SUN e GARDERS, 1990). Têm origem na América tropical e encontram-se distribuídas em todas as regiões agricultáveis do Brasil. Uma única planta pode produzir até 3000 sementes viáveis, demonstrando alto potencial reprodutivo (KISSMANN e GROTH, 1999).

Com densidade de até 15 plantas $\mathrm{m}^{-2}$, cada planta de Bidens pilosa pode reduzir em $2 \%$ o rendimento de grãos em lavouras de soja e em 3\% a matéria seca da planta no florescimento. Esta espécie daninha, na densidade de 170 plantas $\mathrm{m}^{-2}$, reduz $48 \%$ do rendimento de grãos de soja e $52 \%$ da matéria seca da cultura no florescimento (RIZZARDI et al., 2003).

Atualmente o controle seletivo de plantas daninhas dicotiledôneas na cultura da soja é realizado por herbicidas inibidores do fluxo de elétrons no fotossistema II (FS 2), da enzima protoporfirinogênio oxidase (PROTOX) e da enzima acetolactato sintase (ALS). Os herbicidas inibidores do FS 2 são os mais antigos, aplicados em préemergência, em doses relativamente elevadas. Os herbicidas inibidores da PROTOX são aplicados, em sua maioria, em pós-emergência e desempenho eficaz é obtido quando as plantas daninhas estiverem no estágio inicial de desenvolvimento. Os herbicidas inibidores da ALS são os mais empregados, revelando alta eficácia, amplo espectro de plantas daninhas controladas, baixa toxicidade aos mamíferos, alta seletividade em várias culturas, atuando em local específico na planta (VIDAL e MEROTTO JR, 2001).

Plantas daninhas apresentam alta freqüência inicial do alelo resistente aos herbicidas inibidores da ALS em relação à taxa de mutação (VIDAL e FLECK, 1997). Quanto maior a freqüência inicial do alelo de resistência do biótipo, maior a probabilidade ocorrer a seleção natural de indivíduos resistentes na população, em curto período de tempo, com aplicações sucessivas do herbicida. A resistência aos herbicidas inibidores da acetolactato sintetase (ALS) em Lactuca serriola L., foi constatada em apenas cinco anos após o inicio da comercialização de chlorsulfuron (SAARI et al., 1994). Em Lolium rigidum, a freqüência de indivíduos resistentes é de 0,0001\% (PRESTON e POWLES, 2002).

Marcadores moleculares do tipo RAPD (polimorfismo de DNA amplificado ao acaso) permitem avaliar a diversidade genética entre plantas ou microorganismos (WILLIAMS et al., 1990). Esta técnica foi utilizada para avaliar a similaridade genética em biótipos de Bidens pilosa L. e $B$. subalternans DC. resistentes aos herbicidas inibidores da ALS (HERNANDEZ, 2004). Entretanto, não se estudaram biótipos suscetíveis a esses herbicidas. O objetivo deste trabalho foi determinar a similaridade genética entre biótipos resistentes e suscetíveis aos herbicidas inibidores da ALS.

\section{METODOLOGIA}

As sementes e Bidens pilosa provenientes de plantas sobreviventes das aplicações de herbicidas inibidores da ALS foram coletadas em lavouras de soja do Rio Grande do Sul e Paraná. Aproximadamente 2000 sementes foram coletadas por local amostrado. Em cada local foram amostradas pelo menos 50 plantas, distribuídas aleatoriamente na área. Em casa de vegetação as sementes coletadas de Bidens pilosa foram colocadas em potes plásticos (50 sementes por vaso) com volume de $300 \mathrm{~mL}$, preenchido com substrato areia:solo na proporção de 1:1. Na ocasião dessa semeadura também foram semeadas Bidens pilosa sensíveis aos herbicidas inibidores da ALS oriundas de áreas da região de Porto Alegre, para servirem como testemunha.

Os vasos foram colocados em bandejas plásticas com água, para manter o solo constantemente irrigado por capilaridade. A temperatura média do ar durante a condução do experimento foi de aproximadamente $20 \stackrel{\circ}{C}$, e o período de luminosidade, de $12 \mathrm{~h}$ diárias. Quando as plântulas se encontravam no estádio de desenvolvimento de quatro a seis folhas, foram aspergidas com o herbicida chlorimuron (inibidor da enzima ALS) na dose de $40 \mathrm{~g} \mathrm{ha}^{-1}$, utilizando-se pulverizador costal pressurizado com $\mathrm{CO}_{2}$, munido com quatro bicos tipo leque, com pontas $80.02 \mathrm{VS}$, com volume de calda equivalente a $220 \mathrm{~L} \mathrm{ha}^{-1} \mathrm{e}$ pressão de trabalho de $200 \mathrm{kPa}$. A aplicação foi realizada às $16 \mathrm{~h}$ e, na ocasião da aplicação, a temperatura do ar era de $19^{\circ} \mathrm{C}$, com umidade relativa do ar de $75 \%$. Os procedimentos foram repetidos por duas vezes, e os biótipos que sobreviveram aos tratamentos foram confirmados como resistentes.

Após a confirmação da resistência e susceptibilidade, parte das sementes restantes dos biótipos resistentes e suscetíveis foi semeada para coleta de folhas para extração de DNA vegetal em julho de 2004. Os biótipos utilizados e a sua origem encontram-se na Tabela 01. Foram coletadas de duas a três folhas por planta. As folhas foram colocadas em tubos de $1,5 \mathrm{~mL}$ e acondicionadas em caixas térmicas com gelo para evitar a oxidação do material, sendo posteriormente armazenadas à $-20 \stackrel{\circ}{ } \mathrm{C}$.

O DNA das folhas foi extraído conforme o protocolo de extração que utiliza os detergentes, Brometo de Cetiltrimetilmônio (CTAB) e Dodecil Sulfato de Sódio (SDS 20\%) (MURRAY e THOMPSON, 1980). As amostras foram submetidas à leitura em espectrofotômetro a 260 e $280 \mathrm{~nm}$ para análise da quantidade e qualidade do DNA genômico. As reações de RAPD foram preparadas para um volume final de 25 ìL, contendo a solução tampão da enzima Taq DNA polimerase (20 mM Tris$\mathrm{HCl}$ e $50 \mathrm{mM} \mathrm{KCl}$ ), 0,2 mM de cada dNTP, 1,5 mM de $\mathrm{MgCl} 2,0,30$ ì de primer; 20 ng de DNA e 1,2 unidades da enzima Taq DNA polimerase.

A seleção dos primers utilizados no experimento foi realizada com base no polimorfismo apresentado no trabalho de HERNANDEZ (2004). Foram selecionados 14 primers (OPAD 01; OPAD 08; OPAD 17; OPAD 18; OPAG 01; OPAI 14; OPAI 19; OPE 09; OPE 12; OPP 05; OPP 06; OPP 08; OPP 09; OPP 10) provenientes da empresa Operon Techonologies (Alameda, CA).

As reações de PCR (Polimerase Chain Reaction) foram realizadas em termociclador PTC 100 (Programmable Thermal Controller MJ Research, INC), programado para um passo inicial de $94{ }^{\circ} \mathrm{C}$ por $1 \mathrm{~min}$, seguido de 35 ciclos de $1 \mathrm{~min}$ a 
$94{ }^{\circ} \mathrm{C}, 1$ min a $35^{\circ} \mathrm{C}$ e 1 min a $72{ }^{\circ} \mathrm{C}$. Uma incubação de $10 \mathrm{~min}$ a $72{ }^{\circ} \mathrm{C}$ foi incluída como passo final.

Os produtos amplificados foram analisados por eletroforese em gel de agarose $1,5 \%$, submetido a uma tensão elétrica de $110 \mathrm{~V}$ por $2 \mathrm{~h}$, em tampão TBE, $0,5 \times\left(0,1 \mathrm{M}\right.$ Tris, $0,012 \mathrm{ng} \mathrm{mL}^{-1}$ brometo de etídio, 1 M Ácido bórico, 0,5 M EDTA) padronizandose a migração. Os géis foram visualizados em transluminador UV. O tamanho dos fragmentos foi determinado com a utilização do programa Kodak EDAS 290 (Eletrophoresis Documentation and Analysis System) comparando com o padrão DNA Ladder $100 \mathrm{pb}$.

Os dados foram analisados de acordo com presença (1) ou ausência (0) de bandas. O coeficiente para o cálculo de similaridade genética utilizada para a análise dos indivíduos foi o de Jaccard (ROHLF, 2000). Com os dados de similaridade foi realizada a análise de agrupamento (módulo SAHN), utilizando o método da média das distâncias genéticas (UPGMA-). Para a construção da árvore filogenética foi utilizado o programa computacional Numerical Taxonomy and Multivariate Analysis System (NTSYS) (ROHLF, 2000). A estabilidade dos agrupamentos foi testada pelo procedimento de remontagem com 10000 repetições. O coeficiente médio de similaridade foi determinado através da média aritmética de todas as similaridades das amostras entre si.

\section{RESULTADOS E DISCUSSÃO}

Todos os primers analisados foram polimórficos. A média do número de locos polimórficos por primer foi de 3,12 , e a da porcentagem de locos polimórficos de $38,81 \%$. Um total de 63 bandas amplificadas foram avaliadas e variaram entre 300 e 1050 pares de base (Tabela 1 e Figura 1).

TABELA 1 - Biótipos utilizados, a sua origem, número de acessos utilizados e a sua susceptibilidade aos herbicidas inibidores da enzima ALS.

\begin{tabular}{lccc}
\hline Biótipos & Origem & Número do(s) acesso(s) utilizado(s) & Suscetível \\
\hline POA 2 & Porto Alegre - RS & 7 & Sim \\
POA 9 & Porto Alegre - RS & 6 & Sim \\
COL 5 & Colorado - RS & $1,2,3,4,5,6,7,8,10,11,12$ & Não \\
PAB 6 & Pato Branco-PR & $5,6,7,9,12$ & Não \\
PAB 7 & Pato Branco-PR & $3,4,6,7,10,11$ & Não \\
\hline
\end{tabular}

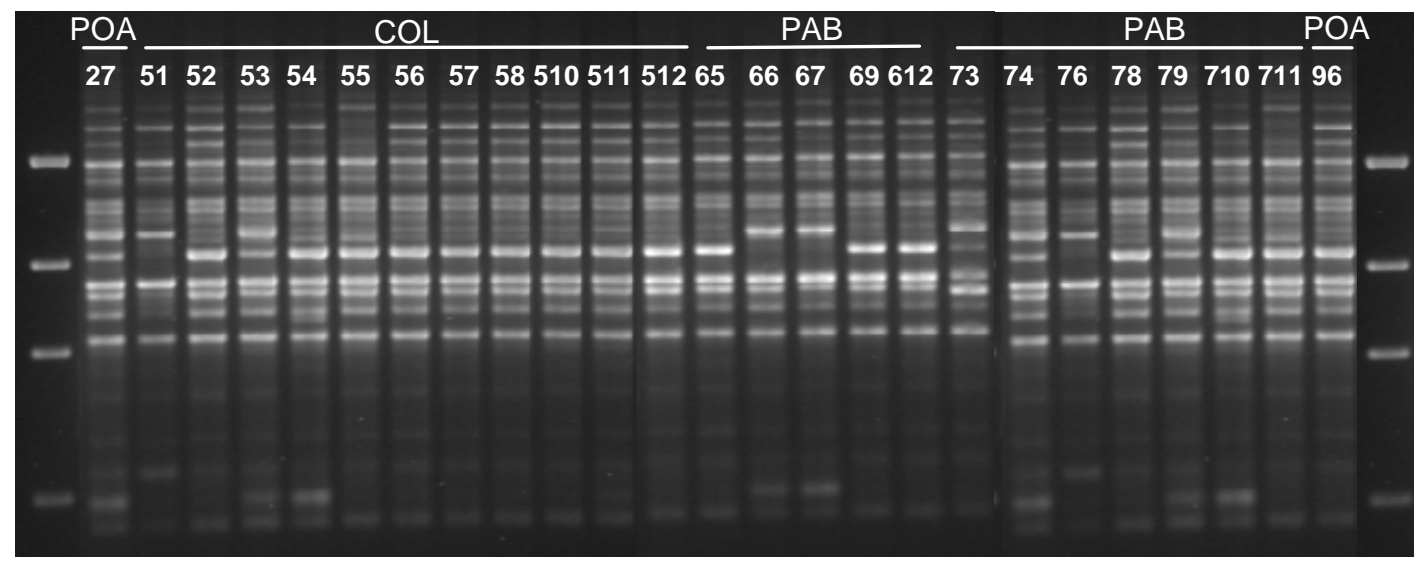

FIGURA 1 - Perfil de um gel de RAPD utilizando o primer OPAD 01 em 25 acessos de Bidens pilosa coletados nos municípios de Porto Alegre - RS (POA), Colorado - RS (COL) e Pato Branco - PR (PAB).

O coeficiente médio de similaridade genética foi de $43 \%$. Este valor é similar ao obtido em outras espécies daninhas onde o coeficiente utilizado para o cálculo de similaridade genética para a análise de indivíduos foi o de Jaccard foi realizada através do método da média das distâncias genéticas (UPGMA). Por exemplo, para Bidens pilosa e $B$. subalternans resistentes aos herbicidas inibidores da ALS, coletadas no Sul e Centro-oeste do Brasil, o coeficiente médio de similaridade genética encontrado foi baixa, variando entre $22 \%$ e $50 \%$, respectivamente (HERNANDEZ, 2004). Para B. pilosa, suscetível e resistente aos herbicidas inibidores da ALS, coletada no estado do Paraná, a similaridade genética média foi de $37 \%$ (VIDAL et al., 2005). Para Euphorbia heterophylla oriunda do estado do Rio Grande do Sul foi encontrada similaridade de $40 \%$ (WINKLER et al., 2003). Porém, Eichornia crassipes apresentou alta similaridade genética, próxima de $90 \%$, o que se explica pela propagação vegetativa, que exclui a possibilidade de recombinação genética (CARDOSO et al., 2002).

Os 25 acessos de Bidens pilosa analisados geraram 4 grupos distintos (Figura 2). No grupo 1, ficaram agrupados 13 acessos resistentes e 2 suscetíveis, com origens geográficas distintas. Neste grupo ficaram agrupados 2 acessos suscetíveis do município de Porto Alegre (POA 27 e 96) e a maioria dos acessos do município de Colorado (COL 51, 54, 57, 56, 58, 511, 52, 510, 512) e do município de Pato Branco (PAB 711, 710, 74, 78). 


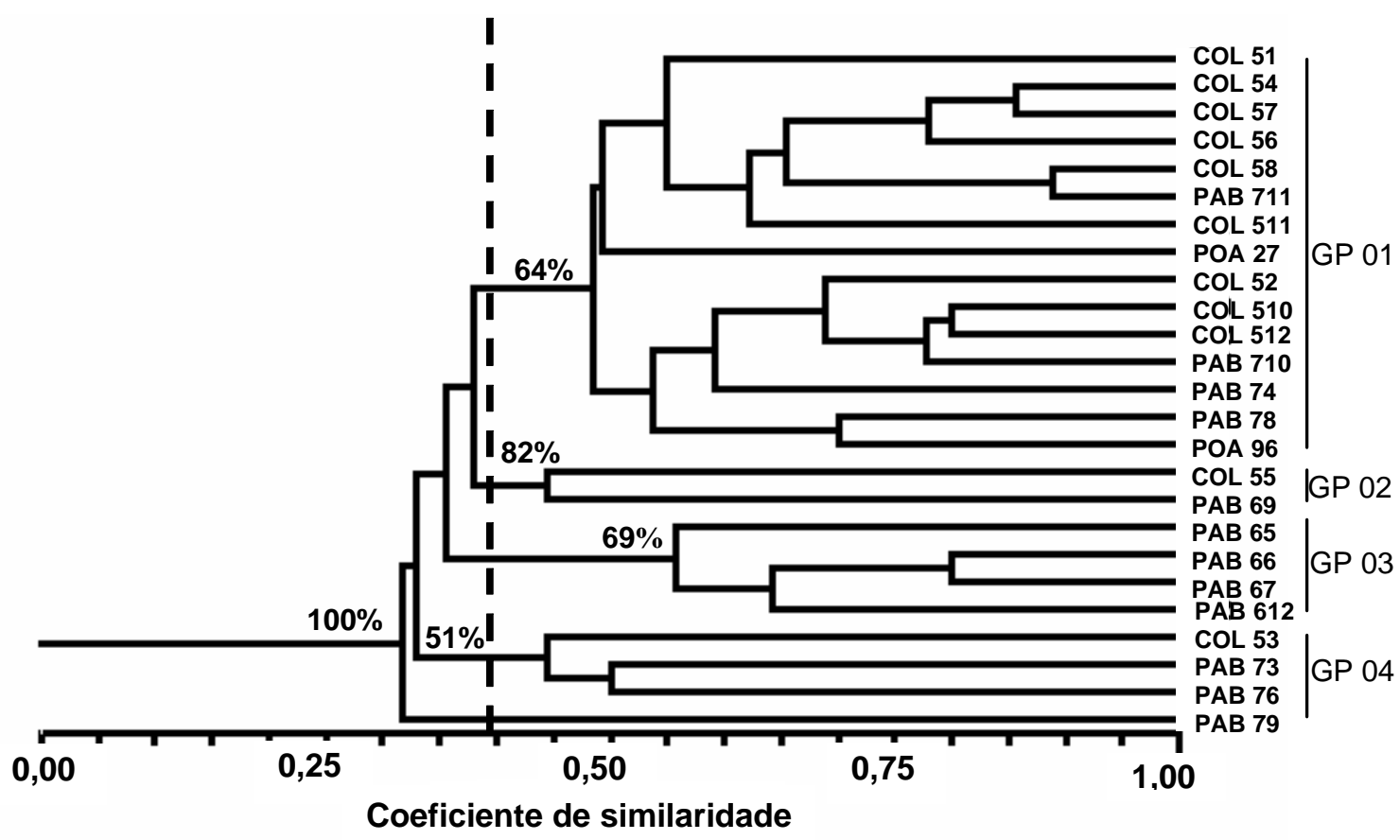

FIGURA 2 - Dendograma de similaridade genética entre 25 acessos de Bidens pilosa dos estados do Rio Grande do Sul e Paraná, com os respectivos coeficientes de similaridade.

No grupo 2, ficaram agrupados 2 acessos resistentes dos biótipos de Colorado e Pato Branco (COL 55 e PAB 69). No grupo 3, se agruparam 4 acessos do biótipo resistente de Pato Branco (PAB $65,66,67,612)$. No grupo 4 , agruparam 3 acessos dos biótipos resistentes de Colorado e Pato Branco (COL 53 e PAB 73, 76). E o acesso PAB 79, resistente de Pato Branco, se diferenciou dos demais acessos.

Nos grupos 1, 2 e 4 ficaram agrupados acessos com origens geográficas distintas. Esperase que os acessos de um mesmo local ficassem num mesmo grupo. Porém, devido à alta variabilidade genética (baixa similaridade genética) dentro de uma mesma população e os $10 \%$ de fecundação cruzada possíveis em Bidens pilosa, que facilita o fluxo gênico, isto não ocorre. Aparentemente, o sistema avançado de dispersão das sementes da espécie (zoocoria) facilitou o fluxo gênico por sementes. É possível que alguns acessos oriundos de municípios distintos tenham sido agrupados em uma única classe devido a sua origem comum, possivelmente junto com sementes de espécies cultivadas contaminadas com Bidens pilosa ou através de aves migratórias. Nas Filipinas, analisando a qualidade das sementes de Oriza sativa foi observado que $50 \%$ das amostras apresentavam sementes de plantas daninhas (HUELMA et al., 1996). Na Europa, Solanum nigrum resistente as triazinas pertencentes a seis biótipos poloneses foram geneticamente similares com indivíduos de um biótipo francês, sendo que a possível forma de dispersão das sementes de Solanum nigrum se deu através da migração de pássaros como o Turdus pilaris L. e o Sturnus vulgaris L. (STANKIEWICZ et al., 2001).
O fato de que acessos de locais diferentes ficarem num mesmo grupo fazem com que esta espécie possa ter sido introduzida e dispersada a partir de poucos materiais genéticos. Isso poderia justificar a similaridade genética revelada entre diferentes locais, como é o caso dos grupos 1, 2 e 4 que alocaram acessos de locais distantes geograficamente. Porém, isto demonstra, que o centro de origem dessa espécie não está localizada nesta região.

Os indivíduos suscetíveis (POA 27 e 96, grupo 1) ficaram agrupados em uma classe distinta, porém, não foi possível, através da técnica de RAPD, diferenciá-los dos indivíduos resistentes.

\section{CONCLUSÕES}

$\mathrm{Na}$ planta daninha Bidens pilosa foi observada reduzida similaridade genética entre os genótipos resistentes e suscetíveis aos herbicidas empregados no seu controle. Sendo uma espécie autógama, com significativa taxa de polinização cruzada (10\%), a variabilidade genética resultante pode explicar os resultados obtidos e a seleção natural de indivíduos resistentes, quando realizado o uso contínuo de herbicidas com o mesmo mecanismo de ação.

\section{AGRADECIMENTO}

A CAPES, CNPq e FAPERGS pelo apoio à pesquisa. 


\section{REFERÊNCIAS}

1. CARDOSO, L.R.; MARTINS, D.; KURAMAR, E.E.; TANAKA, R.H; MORI, E.S. Variabilidade genética de acessos de aguapé coletados no Estado de São Paulo. Planta Daninha, v. 20, n. 1, p. 1-5, 2002.

2. HERNANDEZ, G.C. Resistência de Bidens spp. aos herbicidas inibidores da acetolactato sintase: análise de populações com marcadores moleculares e estratégias para seu manejo. Porto Alegre, 2004. $109 \mathrm{f}$. Dissertação (Mestrado) - Universidade Federal do Rio Grande do Sul, Faculdade de Agronomia, Programa de PósGraduação em Fitotecnia.

3. HUELMA, C.C.; MOODY, K.; MEW, T.W. Weed seeds in rice seed shipments: a case study. International Journal of Pest Management, v. 42, n. 3, p. 147-150, 1996.

4. $\quad$ KISSMANN, K.G.; GROTH, D. Plantas infestantes e nocivas. Tomo I. São Paulo: BASF, 1992, 797 p.

5. MURRAY, M.; THOMPSON, W. F. Rapid isolation of high-molecular-weight plant DNA. Nucleic Acids Reserch, v. 8, n. 19, p. $4321-4328,1980$.

6. PRESTON, C.; POWLES, S.B. Evolution of herbicide resistance in weeds: initial frequency of target site-based resistance to acetolactate synthase-inhibiting herbicides in Lolium rigidum. Heredity, v. 88, n. 1, p. 8-13, 2002.

7. RIZZARDI, M.A.; FLECK, N.G.; AGOSTINETTO, D. Nível de dano econômico como critério para controle de picão-preto em soja. Planta daninha, v. 21, n. 2, p. 273-282, 2003.

8. ROHLF, F.J. Numerical taxonomy and multivariate analysis system. Port Jefferson: Applied Biostatistics, 2000. $38 \mathrm{p}$.

9. SAARI, L.L.; COTTERMAN, J.C.; THILL, D.C. Resistance to acetolactate synthase inhibiting herbicides, In: POWLES, S.B.; HOLTUM LEWIS, J.A.M. (Eds.). Herbicide resistance in plants biology and biochemistry. Boca Raton: CRC Press, 1994. p. 83-139.

10. STANKIEWICZ, M.; GADAMSKI, G.; GAWRONSKI, S.W. Genetic variation and phylogenetic relationships of triazineresistant and triazine-susceptible biotypes of Solanum nigrum - analysis using RAPD markes. Weed Research, v. 41, n. 2, p. 287-293, 2001.

11. SUN, M.; GANDERS, F.R. Outcrossing rates and allozyme variation in rayed and rayless morphs of Bidens pilosa. Heredity, v. 64 , n. 1, p. 139-143, 1990.

12. VIDAL, R.A.; FLECK, N.G. Análise do risco da ocorrência de biótipos de plantas daninhas resistentes aos herbicidas. Planta Daninha, v. 15, n. 2, p. 152-161, 1997.

13. VIDAL, R.A.; LAMEGO, F.P; NUNES, A.L. Otimização do número de primers empregados em RAPD para detectar variabilidade genética entre acessos de picão-preto. Scientia Agraria, v. 6, n. 1-2, p. 71-77, 2005.

14. VIDAL, R.A.; MEROTTO JÚNIOR, A. Herbicidologia. Porto Alegre: Evangraf, 2001. 152 p.

15. WILLIAMS, J.G.K; KUBELIC, A.R; LIVAK, K.J; RAFALSKI, J.A; TINGEY, S.V. DNA polymorphisms amplified by arbitrary primers are useful as genetic markers. Nucleic Acids Research, v. 18, n. 22, p. 6531-6535, 1990.

16. WINKLER, L.M.; VIDAL, R.A.; BARBOSA NETO, J.F. Caracterização genética de Euphorbia heterophylla resistente aos herbicidas inibidores da acetolactato sintetase. Pesquisa Agropecuária Brasileira, v. 38, n. 9, p. 1067-1072, 2003. 
